\title{
Cost of Photochemical Machining
}

\author{
RAJKUMAR ROY, DAVID ALLEN, and OSCAR ZAMORA
}

School of Industrial and Manufacturing Science, Cranfield University, UK Email: \{r.roy,d.allen\}@cranfield.ac.uk

\begin{abstract}
Photochemical machining (PCM), also known as photoetching, photofabrication or photochemical milling, is a non-traditional manufacturing method based on the combination of photoresist imaging and chemical etching. PCM uses techniques similar to those employed for the production of printed circuit boards and silicon integrated circuits. The PCM industry plays a valuable worldwide role in the production of metal precision parts and decorative items. Parts produced by PCM are typically thin, flat, and complex. These parts have applications in electronics, mechanical engineering, and the aerospace industry. The increasing popularity of industrial applications, together with greater competition, means that there is a need to understand the costs involved in PCM so that the right technology can be selected for manufacturing. The paper identifies the costs involved in Photochemical Machining and presents a cost model for PCM using a bottom-up approach. The research used IDEF3 representation (work breakdown structure, WBS) to identify the process used in PCM. Expert interview, literature survey, and participant observation were used to identify cost drivers at each stage of the manufacturing process. The WBS and the cost drivers were used to develop the cost model, which is focused on stainless steel machining. Spreadsheets were used to implement the model, while the workbook is divided according to the main process steps and general costs. The worksheets contained in this workbook are: General Costs, Produce Drawing, Process Phototool, Select Metal, Prepare Metal, Coat the Metal, Process Photoresist, Etch Metal, Strip Photoresist, and Check \& Package. Each of these sections is divided into the following types of costs: Materials, Direct Labour, Environmental and Indirect Costs. The workbook contains relevant data acquired from the PCM laboratory at Cranfield, PCM industry, and literature. The model is validated through expert judgement obtained on case study results. The model presented in this paper can be extended to include other PCM techniques to machine other materials.
\end{abstract}

\section{INTRODUCTION}

The Photo Chemical Machining (PCM) industry plays a major worldwide role in the production of flat precision parts and decorative items. PCM, also known as photoetching, photofabrication or photochemical milling (Allen, 1986), is a nontraditional manufacturing method based on the combination of photoresist imaging and chemical etching. There is considerable interest in the need to understand the 
costs associated with the PCM process. This paper identifies cost drivers for the technique, and presents a methodology to develop a cost model for the process.

PCM works on most metals, and uses techniques similar to those employed for the production of printed circuit boards and silicon integrated circuits. Parts produced by PCM are typically thin, flat and, complex. These parts include applications in the electronics, filter, and aerospace industry, while typical products produced by PCM include:

- $\quad$ Suspension head assemblies for hard disk drive technology.

- Shadow masks, which are an essential component in colour tubes for televisions and computers.

- Integrated Circuit (IC) leadframes that provide the contacts for the microprocessor and its support.

- Decorative items, where the price of the product has to be low, their complexity high, and the batches not very numerous.

- Prototyping, where PCM is used because the tooling effort is low, the lead-time short, and the precision high.

The PCM manufacturing process begins by cleaning the metal and coating it with a light-sensitive resist. The coated sheet is then exposed to ultra violet light through the photomaster from both sides, hardening the photoresist where exposure takes place. The unexposed areas are developed away, thereby removing the resist and leaving the metal bare where etching will occur. Etching solution is sprayed under pressure onto the top and bottom surfaces, accurately producing the component by removing the unwanted metal. The resist is then removed to leave burr- and stressfree precision components (Attewell, 2002).

The paper presents a Cost Model for the PCM process. A Cost Model is a set of systematically-arranged mathematical relationships. Quantities and prices are the inputs for these equations, while cost estimates are the outputs. Historical data available from the company, basic engineering principles, characteristics of the manufacturing process, and various economic assumptions (NASA, 2002) are used to obtain the Cost Estimating Relationships (CER).

Cost models are used primarily to reduce costs during the design phase of the product development cycle. Different applications of cost modelling can be summarised as follows:

- $\quad$ Business process re-engineering: By understanding the cost of a process, the activities that are causing major costs can be improved and the improvement measured.

- Cost controlling: If an accurate process cost can be obtained, the budget for this process will be set at a certain level. Problems can be addressed by identifying the areas that produce the greatest expenditure.

- $\quad$ Costing products: The model will help in estimating the cost of a product.

The paper is structured into six sections. The next section presents an overview of related research. The third section describes a Work Breakdown Structure (WBS) for PCM. The fourth section identifies the cost drivers at different stages of the 
manufacturing process, and presents the cost model and its development stages. The fifth section presents some data collection and the cost model validation. The final section discusses the results, conclusions, and future work. Overall, the paper illustrates an application of existing cost modelling techniques in the new domain of Photo Chemical Machining (PCM); it also provides a better understanding of PCMrelated cost issues.

\section{COST ENGINEERING AND PCM}

Cost estimating consists of sequential operations that require either numeric inputs or selected descriptive details of the specific estimate. A cost model consists of a set of mathematical relationships arranged in a systematic sequence to formulate a cost methodology in which outputs, namely cost estimates, are derived from inputs such as quantities and prices. Costing is the technique used to estimate the resources required for carrying out a project (project cost) or the total cost of producing a product (product cost).

Cost models have two main purposes in manufacturing: when the process is established and during the design stage. Therefore, by examining the cost at the design stage, it is possible to reduce manufacturing cost by using information to make better design decisions (Swardt, 1998). Cost models play an important role during the design of a process or a product by indicating how much it will cost to use a determinate process, material, or product. The main reasons for estimating costs either before or during the early phases of design are to (Bolton, 2003):

- $\quad$ Predict the resources required for the project.

- $\quad$ Illustrate the financial consequences for the company.

- Justify the design and development time proposed.

- $\quad$ Demonstrate the viability of the product in relation to the market.

During the detailed design phase, the reasons for estimating cost are to (Bolton, 2003):

- $\quad$ Review project progress and budget.

- $\quad$ Revise earlier estimates and predictions.

- $\quad$ Estimate the component manufacturing and delivery costs.

- $\quad$ Establish the costs of bought-out components and units.

- Compare the costs of competing design proposals.

- $\quad$ Confirm estimates of potential profit margins.

- $\quad$ Confirm the estimated selling price.

Cost models have been used to establish manufacturing process when carrying out business process re-engineering (NASA 2002). Cost modelling is also used within the semiconductor industry, for budgeting and cost control; measuring compliance performance; determining reimbursements, and setting fees (Veltri, 2003). A major application of cost estimation is the identification of features of pieces, costing them, and entering them into a database (Chen et al., 1998). 
a) There are different types of cost modelling techniques, such as bottom-up, specific analogy, parametric, cost review and update and expert opinion (NASA 2002).

Cost Estimation Relationships (CERs) are an important tool available to the estimator. These relations are in the form of cost factors, equations, curves, monograms, and rules of thumb. A statistical CER can be derived from information based on past occurrences, although historical data is not always a reliable guide to the future. Therefore, great care must be taken when extrapolating the relationship from the sample. The estimator must decide whether the cost estimating relationship is relevant or how it can be modified to be useful.

The purpose of the cost model development process is to identify and collect information on products, processes, and costs, and to analyse this information in order to quantify the CER that exist (Delgado et al., 2002). The most common steps in cost modelling involve determination of the (Brinke, 2002):

- $\quad$ Scope, i.e. costs subdivided in different types, which have to be modelled.

- $\quad$ Allocation base for (overhead) costs.

- $\quad$ Cost functions, i.e. the relation between product parameters and costs.

A review of the literature on the cost model development process indicated that, for the present project, it would be more useful to develop a specific approach by combining the previous ones. This new development process was necessary because the previous ones were for other types of project or for people who were working in this area for many years.

Previous work in the research area involved the development of Computer Aided Process Planning, Cost Estimating and Job Loading for PCM (Singh, 1988). It is no longer possible to use the computer programme developed, although it is useful for this current research because it was developed for a particular factory and a large amount of data was available. The current author was able to extract some CERs from this data and apply it to the present work. The costing criteria used in the afore-mentioned work were as follows (Singh, 1988):

- Batch size: A production batch of 100 or more is economical. It is necessary to apply a "nesting factor" if the batch is less than this number.

- Lead time: The deliverable time for an order influences the cost of the parts because the production has to be recalculated and all efforts have to be centred on producing the parts in a short time.

- Work order preparation cost: If the order is new, it needs more preparation (planning, phototooling and administrative charges) than if it is repeated.

- Work tolerance: Less work tolerance requires more process control.

- Operation costs: The manufacturing costs of the PCM process steps and some post operation were quantified. 
Other useful references about etchant regeneration include increasing the utilisation efficiency of ferric chloride (Allen and Ler, 1999).

\section{THE PCM PROCESS WBS}

A WBS for the PCM process was developed to obtain a list of the operations involved in this manufacturing method for stainless steel machining (Zamora 2003). Associated costs could then be assigned to the operations. The development of the cost model depended on the identification of the costs drivers obtained from this analysis. In order to develop both the process WBS and the associated cost of operations, it was necessary to gain understanding of the PCM process. It was also necessary to represent the manufacturing process and to select the activities to which costs needed to be assigned. It must be noted that some activities or operations are optional, and that alternative methods can be used to carry them out.

An understanding of the PCM process was developed through both literature review and visits to the PCM laboratory located at Cranfield University. A process map of the PCM process was developed, and the main activities for the cost model selected. The reasoning behind this selection was that certain techniques were no longer used and so it was not necessary to include them. In other cases, the map of an operation contained too many activities and so they had to be included in a general one.

Figure 1 illustrates the general process map created using IDEF3 notations. Some of the main steps of the process include sub-operations that were considered for obtaining the cost drivers.

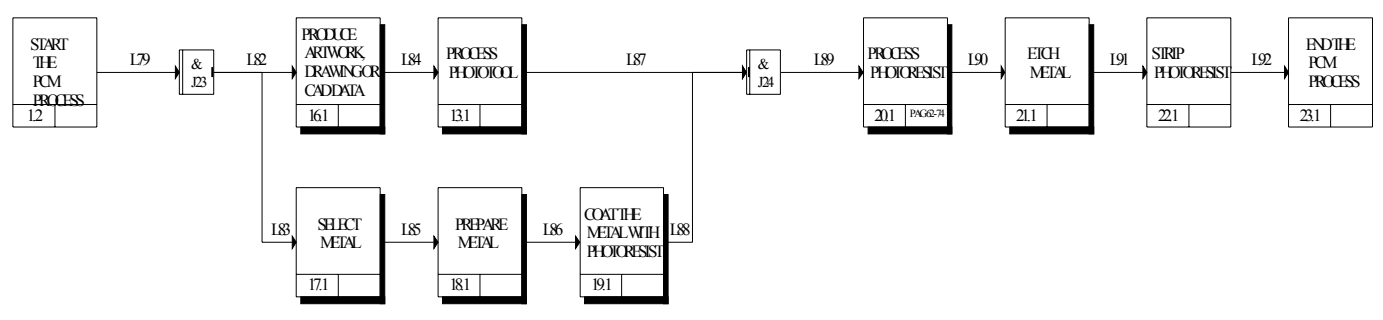

Figure 1. General Process Map

\section{COST DRIVERS AND COST MODEL DEVELOPMENT}

The general Process Map for PCM provided the basis to identify the different elements of costs involved in the process. These cost elements are the cost drivers for PCM. Costs for each sub process is divided into five categories: material, direct labour, use of equipment, environmental and indirect. Table 1 shows the full list of cost drivers involved in the process. The cost drivers were derived through literature review and expert interview within Cranfield University and one company. 
The cost model was created in such a way that enabled data for a factory to be introduced easily. This data is linked through the model, and so the model can be used in a particular factory without the need to change anything. The cost of using PCM was represented by filling the cost model with data. The is a Bottom-up approach in estimating the cost.

Since the cost model was not developed for a particular factory, it is necessary to clearly show the costs considered in establishing the manufacturing costs. For this reason, a file was created to show all cost generators. An additional file was created to include all possible options of the manufacturing process. Since this information would show too many options, which could or could not be included in the costs, it could not be included in the cost per section file. The following paragraphs provide a general overview of how the cost model works. In order to run the model, the following three workbooks must be open: PCMCostModel.xls, CostPerSection.xls and Options.xls .

The first page of the PCMCostModel.xls shows the author's contact details and the project title. The second page contains instructions on how to use the cost model. The third page shows the order in which the attributes have to be selected so that the cost of a particular batch of pieces can be identified. The Calculation Assumptions are located on the next page of the workbook. This page shows the data used for the cost calculation; the data can be altered for a particular factory. The fifth page is used for performing calculations on the data. The next page is the cost model resume, which details the cost per batch and per piece at different stages of the manufacturing process. The next worksheet contains links to the CostPerSection.xls file; clicking on each box of the process step enables the cost included in this stage to be displayed. The last page of this workbook contains a list of the options that can be selected in the Attributes worksheet. These cost factors are written for the different options.

CostPerSection.xls is the second of the three workbooks; it shows the costs considered at each stage of the PCM process. The workbook is divided into the main process steps (see figure 1) and General Costs. The workbook contains the following worksheets:
0. General Costs
1. Produce Drawing
2. Process Phototool
3. Select Metal
4. Prepare Metal
5. Coat the Metal
6. Process Photoresist
7. Etch metal
8. Strip Photoresist
9. Check \& Package 
Table 1: List of Cost Drivers for the PCM Process

\begin{tabular}{|c|c|c|c|c|c|}
\hline CATEGORY & MATERIALS & DIRECT LABOUR & USE OF EQUIPMENT & |ENVIRONMENTAL & INDIRECT \\
\hline \multirow[t]{4}{*}{ General Costs } & METAL & PROCESS SUPERVISOR & $\begin{array}{l}\text { MANUFACTURING FLOOR } \\
\text { USE }\end{array}$ & & $\begin{array}{l}\text { PLAN THE } \\
\text { PRODUCTION }\end{array}$ \\
\hline & ELECTRICITY & MAINTENANCE & OFFICE EQUIPMENT & & \\
\hline & & PARTS QUALITY CHECK & QUALITY EQUIPMENT & & \\
\hline & & PLAN THE PRODUCTION & & & \\
\hline & & & & & \\
\hline \multirow[t]{2}{*}{\begin{tabular}{|l|} 
Produce Drawing \\
Costs
\end{tabular}} & & LABOR OF DRAW THE PIECE & $\begin{array}{l}\text { EQUIP. FOR DRAW THE } \\
\text { PIECE }\end{array}$ & & $\begin{array}{l}\text { OFFICE } \\
\text { EQUIPMENT }\end{array}$ \\
\hline & & $\begin{array}{l}\text { LABOR OF DRAW THE } \\
\text { PHOTOTOOL }\end{array}$ & $\begin{array}{l}\text { EQUIP. FOR DRAW THE } \\
\text { PHOTOTOOL }\end{array}$ & & \\
\hline & & & & & \\
\hline \multirow[t]{2}{*}{\begin{tabular}{|l|}
$\begin{array}{l}\text { Process Phototool } \\
\text { Costs }\end{array}$ \\
\end{tabular}} & RAW PHOTOTOOL & $\begin{array}{l}\text { LABOUR TO DO A } \\
\text { PHOTOTOOL WITH LASER }\end{array}$ & $\begin{array}{l}\text { LASER PATTERN } \\
\text { GENERATOR MACHINE }\end{array}$ & & \\
\hline & & $\begin{array}{l}\text { LABOUR TO DO A } \\
\text { PHOTOTOOL WITH } \\
\text { PHOTOPLOTTER } \\
\end{array}$ & $\begin{array}{l}\text { PHOTOPLOTTER PATTERN } \\
\text { GENERATOR MACHINE }\end{array}$ & & \\
\hline \multirow{3}{*}{ Select the Metal Costs } & & & & & \\
\hline & & $\begin{array}{l}\text { LABOR TO SELECT THE } \\
\text { METAL }\end{array}$ & & & $\begin{array}{l}\text { OFFICE } \\
\text { EQUIPMENT }\end{array}$ \\
\hline & & & & & \begin{tabular}{|l|} 
TOOLS TO \\
SELECT THE \\
METAL (BOOKS, \\
\end{tabular} \\
\hline & & & & & \\
\hline \multirow[t]{6}{*}{$\begin{array}{l}\text { Prepare the Metal } \\
\text { Costs }\end{array}$} & ALKALI & $\begin{array}{l}\text { OPERATOR FOR CLEANING } \\
\text { PROCESS }\end{array}$ & ALKALI CLEANING MACHINE & ALKALI DISPOSAL & \begin{tabular}{|l} 
TEST THE \\
MATERIAL
\end{tabular} \\
\hline & WATER & $\begin{array}{l}\text { OPERATOR FOR CUTTING } \\
\text { THE METAL }\end{array}$ & ALKALI WASHING MACHINE & ACID DISPOSAL & \\
\hline & ACID & & ACID CLEANING MACHINE & & \\
\hline & & & ACID WASHING MACHINE & & \\
\hline & & & DRYING MACHINE & & \\
\hline & & & CUTTING MACHINE & & \\
\hline & & & & & \\
\hline \multirow[t]{2}{*}{ Coat the Metal Costs } & $\begin{array}{l}\text { DRY } \\
\text { PHOTORESIST }\end{array}$ & $\begin{array}{l}\text { DRY PHOTORESIST } \\
\text { OPERATOR }\end{array}$ & $\begin{array}{l}\text { DRY PHOTORESIST } \\
\text { MACHINE }\end{array}$ & \begin{tabular}{|l|} 
DISPOSAL OF \\
POLYETHYLENE \\
PROTECTION FILM \\
\end{tabular} & \\
\hline & $\begin{array}{l}\text { LIQUID } \\
\text { PHOTORESIST }\end{array}$ & $\begin{array}{l}\text { LIQUID PHOTORESIST } \\
\text { OPERATOR } \\
\end{array}$ & $\begin{array}{l}\text { LIQUID PHOTORESIST } \\
\text { MACHINE } \\
\end{array}$ & $\begin{array}{l}\text { SOLVENT } \\
\text { DISPOSAL } \\
\end{array}$ & \\
\hline & & & & & \\
\hline \multirow[t]{4}{*}{\begin{tabular}{|l|} 
Process Photoresist \\
Costs \\
\end{tabular}} & & $\begin{array}{l}\text { PROCESS PHOTORESIST } \\
\text { OPERATOR }\end{array}$ & UV MACHINE & DISPOSAL OF PET & \\
\hline & & $\begin{array}{l}\text { OPERATOR FOR POST- } \\
\text { DEVELOPING }\end{array}$ & DEVELOPMENT MACHINE & & \\
\hline & & & CLEANING MACHINE & & \\
\hline & & & POST-DEVELOPMENT OVEN & & \\
\hline \multirow[t]{2}{*}{ Etch Metal Costs } & FERRIC CHLORIDE & ETCH OPERATOR & BATCH ETCHER & \begin{tabular}{|l|} 
FERRIC CHLORIDE \\
REGENERATION \\
PROCESS \\
\end{tabular} & \\
\hline & & & CONVEYORISED ETCHER & \begin{tabular}{|l|} 
FERRIC CHLORIDE \\
TREATMENT \\
OUTSIDE THE \\
\end{tabular} & \\
\hline & & & & & \\
\hline \multirow[t]{3}{*}{\begin{tabular}{|l}
$\begin{array}{l}\text { Strip Photoresist } \\
\text { costs }\end{array}$ \\
\end{tabular}} & & STRIPPPING OPERATOR & STRIPPING EQUIPMENT & & \\
\hline & & & RINSING EQUIPMENT & & \\
\hline & & & DRYING EQUIPMENT & & \\
\hline \multirow{3}{*}{$\begin{array}{l}\text { Check and Package } \\
\text { Cost }\end{array}$} & & & & & \\
\hline & $\begin{array}{l}\text { PACKAGING } \\
\text { MATERIALS }\end{array}$ & |PACKAGING LABOUR & PACKAGING EQUIPMENT & & \\
\hline & & CHECK QUALITY PARTS & QUALITY EQUIPMENT & & \\
\hline
\end{tabular}

The Attributes sheet of the PCMCostModel.xls allows different options to be selected. In order not to show an extensive list of costs that are actually included, an option selected from this workbook takes the information from the options.xls. This page displays the data resulting from the cost calculations performed in the assumptions sheet in PCMCostModel.xls. Although the worksheets are for each 
different cost option that can be included in the costs, Options.xls has the same format as CostPerSection.xls. The purpose of Options.xls workbook is to store the different options and techniques that can be considered for an order or a particular sub process. The final structure of the three workbooks was completed after several iterations with domain experts at Cranfield University and in the supporting company.

\section{DATA COLLECTION AND COST MODEL VALIDATION}

Following construction of the cost model, a list of all the data necessary to calculate the cost was obtained. In order to check if the cost model produces accurate results data was collected and the cost of producing a part was calculated with the accuracy expected from that the data. The data was collected from multiple sources:

- Enterprise Integration Department

- Literature Review

- Product Suppliers

- Machine Manufacturers

- PCM industries or experts

Due to confidentiality issues, the data cannot be published in the paper. The industry is also sensitive to cost data information and there is also a possibility of bias in data obtained from the companies.

The cost model validation took place in two stages: verification and validation. In the verification stage, the model is checked for any manual error in developing the model. The validation of the cost model was performed through case study and expert opinion after using the model. The validation process fine-tuned the performance of the cost model by changing some data and cost drivers.

\section{CONCLUDING REMARKS}

This research has led to the development of a new cost model for Photo Chemical Machining. The paper presents the cost involved in using Photochemical Machining. The PCM process was identified and structured using the IDEF3 methodology. The IDEF3 maps were used to assign the cost drivers of each operation and to structure the cost model. The cost drivers for the PCM manufacturing process have been identified and documented. A cost model for PCM has been created and is now in use. It can be used to visually check what costs have been considered and to explain how the cost is obtained. The cost model can be used by the PCM industry for activities such as product costing, process optimisation, and cost controlling. Cranfield can also use the model to carry out future projects, such as comparing different techniques that can be used to produce a part by PCM. The model presented in this thesis is more suitable for stainless steel machining. The cost model should be extended to include other PCM techniques to machine other materials. 


\section{REFERENCES}

Allen D. M. (1986) The Principles and Practice of Photochemical Machining and Photoetching, The Institute of Physics.

Allen, D. M. and Ler L. T. (1999). Increasing utilisation efficiency of ferric chloride etchant in industrial photochemical machining, J. Environ. Monit., 1, 103108.

Attewell. (2002). Photo Chemical Machining Process. Internet resource: http://www.attewell.co.uk/pcm/process.htm. (accessed 26th July 2003).

Baker V. (2001) Full Service Supplier Cost Modelling. MSc Thesis Cranfield University, 2001.

Bolton Institute. (2003) Chapter 3-Costing in Design and Development. Internet: http://www.bolton.ac.uk/campus/desmech/capd/cap4013/restricted/chap3/cap40130 3.html. (accessed 21st July 2003)

Brinke E. (2002). A Cost Estimation Tool Applied in the Sheet Metal Domain., Ipskamp, Enschede, The Netherlands, 2002.

Chen Y. M. and Liu J. J. (1999) Cost-effective design for injection moulding. Robotics and Computer-Integrated Manufacturing, 15, 1999.

Delgado Y., McNeill M. and Stockton D. (2002) Improving the Cost Model Development Procedure. AACE International Transactions, EST.14, 2002.

ECOM. (2003) Cost Modelling: A General Description. Internet Resource: http://www.estec.esa.nl/eawww/ecom/article/ecom.htm\#Chap3. (accessed 7th July 2001).

NASA. (2002) Cost Estimating Handbook. U.S. Internet Source: http://www.jsc.nasa.gov/bu2/NCEH/index.htm (accessed on 10 ${ }^{\text {th }}$ December 2003).

Singh V. (1988) A Computer Aided Process Planning, Cost Estimating and Job Loading System for Photochemical Machining, MSc Thesis, Cranfield University.

Stockton D. J., Foster R. and Messner B. (1998) Developing Time estimating Models for Advanced Composite Manufacturing Processes. Aircraft Engineering and Aerospace Technology, Nov/Dec 1998. 
Swardt, V. (1998) A Manufacturing Time and cost Estimation Model For Large Fabricated Assemblies, University of Stellenbosch.

Veltri A., Dance D. and Nave M. (2003) SH\&E Life-Cycle Cost Model, Professional Safety, Oakton, USA, July 2003.

Zamora, O. (2003) Development of a Cost Model for Photochemical Machining, MSc Thesis, Cranfield University, UK. 